Research article

\title{
Isolation and characterization of hemagglutinins from Clerodendrum phlomidis L.f.
}

\author{
Aaditi S. Khagar, Prerna S. Khagar, Shubhangi K. Pingle*, Rajani G. Tumane, \\ Aruna A. Jawade and Shraddha Jaiswal \\ National Institute of Miners' Health, JNARDDC Campus, Wadi Nagpur-440023, Maharashtra, India \\ *Corresponding Author: pingle.shubhangi@gmail.com \\ [Accepted: 23 November 2017]
}

\begin{abstract}
Lectins from the leaves, fruit, calyx and stem of Clerodendrum phlomidis plant were isolated after screening of total 54 plants from central India. The crude extract of leaves, fruit, calyx and stem of $C$. phlomidis plant was purified by ammonium sulfate precipitation, followed by dialysis. The isolated lectins of $C$. phlomidis plant were able to agglutinate human as well as dog, hen, goat mouse, mice and fish erythrocytes. The isolated lectins were found to be lactose specific. The pH stability of $C$. phlomidis leaves lectins was between 4-10 pH, for fruit lectins it was 5-7 $\mathrm{pH}$, and for calyx and stem lectins it was found stable in between 4 and $8 \mathrm{pH}$. The calyx and stem lectins were active until $60^{\circ} \mathrm{C}$, fruit has shown activity upto $50^{\circ} \mathrm{C}$ and in case of leaves, it was found maximum $40^{\circ} \mathrm{C}$. Beyond their respective optimum temperature and $\mathrm{pH}$ range, all the lectins were unable to agglutinate erythrocytes. Hemagglutination activity of $C$. phlomidis plant lectins was also checked in the presence of different metal ions and it was found that it was partially inhibited by aluminium metal ion.
\end{abstract}

Keywords: Clerodendrum phlomidis - Hemagglutinine - Lectins - Leguminosae.

[Cite as: Khagar AS, Khagar PS, Pingle SK, Tumane RG, Jawade AA \& Jaiswal S (2017) Isolation and characterization of hemagglutinins from Clerodendrum phlomidis L.f. Tropical Plant Research 4(3): 433-440]

\section{INTRODUCTION}

Lectins are the glycoproteinatious, non enzymatic, non immune origin structures having the ability to bind specifically to carbohydrate moieties (Goldstein \& Poretz 1986). The term lectin was first coined by Boyd and Shapleigh in 1954, which literally means 'to select'. Since they can bind to glycoconjugates present on the surface of red blood cells of humans as well as some of the animals, and agglutinate the cells hence also termed as hemagglutinins (Sharon \& Lis 2004). The lectins are widely distributed among animals, microorganisms and plants. Plants are the abundant source of lectins. Plant lectins or phytolectins are defined as plant proteins possessing at least one non-catalytic domain, which binds reversibly to a specific mono- or oligosaccharides (Peumans \& Damme 1995). The plant family Leguminosae is considered as a rich source of phytohemagglutinin. Plant lectins are involved in the symbiotic relationship between plant roots and symbiotic microorganisms and fungi. Some of the lectins providesdefense against predatory animals and phytopathogens. As compared to animal lectins, plant lectins are easily available to mankind and can utilize their properties in various areas such as ABO blood grouping, cytotoxic, antimicrobial (Lam \& Ng 2010) and antilarval activity (Célia \& Grossi-de-Sa’ 2002).

Clerodendrum phlomidis L.f. is a small herb commonly distributed in India, Sri Lanka, China and Australia, belongs to family Verbenaceae. Clerodendrum phlomidis (CP) commonly known as Agnimatha is a part of important Ayurvedic formulation known as Dasmoolarishta. It is commonly used as an herbal medicine in Indian and China from ancient times. In the present study, lectins were isolated, purified and characterized from various parts of CP such as leaves, fruits, calyx and stem (Sonawane et al. 2014).

\section{MATERIALS AND METHODS}

Chemicals and reagents

The required chemicals such as Ammonium sulphate, Sodium chloride, Dialysis membrane-50, total protein 
kit (Bio-system reagents and chemicals), sugars (Arabinose, mammose, lactose, xylose, galactose, sorbitol, maltose, sucrose, glucose, fructose, ribose) $\mathrm{pH}$ buffers ( $\mathrm{pH} 2-12$ ), Acrylamide, Bis-acrylamide, Coomassie brilliant blue, urea, bromophenol blue, glycerol, TEMED and other chemicals were purchased from Himedia and Serva chemicals.

\section{Selection of plant material}

Total fifty-four plants were screened for the presence of hemagglutination activity, among them Clerodendrum phlomidis is abundant in central India. The plant is authenticated from Botany Department of RTMNU Nagpur University, Nagpur. (Authentication No. CP: 10065). The hemagglutination activity of extracts of study plant were screened against human blood group A, B and O collected from healthy donors and also with some of the animal's blood collected from the veterinary hospital, Nagpur.

\section{Plant extract preparation}

The leaves, fruits, calyx and stems of Clerodendrum phlomidis were separated and washed thoroughly with distilled water and soaked. The separated parts of both plants were homogenized with minimum amount of saline with mortar \& pestle at $4^{\circ} \mathrm{C}$. Around $70 \mathrm{ml}$ of extract was collected by filtering the homogenate with filter paper, centrifuged at $1000 \mathrm{rpm}$ for $10 \mathrm{~min}$. The obtained supernatant was stored at $4^{\circ} \mathrm{C}$ for further use.

\section{Isolation and characterization of lectins from selected plant}

Ammonium sulphate (AS) precipitation of crude extracts: The ammonium sulphate purification relies on decrease in interaction of proteins with water molecules as ammonium sulphate concentration increases from 60 to $90 \%$. The lectins from dialysed extracts precipitate when protein precipitation was done by increasing the concentration of ammonium sulphate by gradual stirring at $4^{\circ} \mathrm{C}$. Ammonium sulphate was removed from theextract by dialysing against normal saline at $4^{\circ} \mathrm{C}$. The dialysis bag having micro pore size $2.4 \mathrm{~nm}$ to easily diffuse small molecules from the pores while traps comparatively big size protein molecules inside the bag. The ammonium sulphate dissolved extract was centrifuged at $1000 \mathrm{rpm}$ for $1 \mathrm{hr}$. The precipitate was collected and dissolved in minimum amount of saline followed by dialyses to remove excess amount of ammonium sulphate.

Protein estimation: Total protein was estimated by using Bio-system kit based on Biuret method, taking Bovin Serum Protein as a standard and measured by semi- autoanalyzer (Gomall et al. 1949).

\section{Heamaglutination activity of isolated CP lectins}

Preparation of 2\% erythrocytes: The human and animal blood samples were collected in heparinized vials and washed 3-4 times with normal saline.One $\mathrm{ml}$ washed RBC's were used to prepare $2 \% \mathrm{RBC}$ 's in $50 \mathrm{ml}$ normal saline and stored at $4^{\circ} \mathrm{C}$ to test the hemagglutination activity against extracts (Olsen 1994).

Hemagglutination Assay: Using 2\% RBC's hemagglutination assay was determined against extracts in 96 microtiter well plate by serial dilution of extracts (Deshpande 2003). The activity was observed by button and carpet pattern formation in the wells. The well-showing carpet was positive for hemagglutination and wells with button pattern considered as inactive dilution for hemagglutination. Hemagglutination unit was calculated by taking reciprocal of minimum dilution showing hemagglutination. The specific hemagglutination activity was defined as a unit per mg protein. Specific activity was calculated in hemagglutination activity.

Hemagglutination Inhibition Assay: The effect of carbohydrate molecules on hemagglutination activity of purified lectins was tested by incubating $100 \mu \mathrm{l}$ extracts with $100 \mu \mathrm{l}$ of $500 \mathrm{mM}$ concentrations of different sugars such as arabinose, maltose, lactose, xylose, galactose, sorbitol, glucose, fructose, ribose, mannose and sucrose (Kurokawa et al. 1976) for $30 \mathrm{~min}$. The inhibition was examined by adding $100 \mu \mathrm{l}$ of $2 \%$ RBC's to each well. The minimum non-agglutinating dilution concentration was considered as threshold inhibitory concentration.

\section{Characterization of CP lectins}

Optimization of $\mathrm{pH}$ for Hemagglutination activity of lectins: The optimum $\mathrm{pH}$ of lectins activity was examined by treating extracts with different $\mathrm{pH}$ range 2-12. For the preparation of $\mathrm{pH}$ buffers, different compositions were used. During assay $100 \mu \mathrm{l}$ of the extract was incubated with $\mathrm{pH}$ buffers for 30 minutes at room temperature and hemagglutination activity was determined against $2 \%$ RBC's. Optimization of $\mathrm{pH}$ was determined by plotting graph of $\mathrm{pH}$ range against percent agglutination (Suseelan et al. 1997).

Optimization of temperature for Hemagglutination activity of lectins: The $200 \mu \mathrm{l}$ aliquots of extracts were incubated at different temperature range $30-100^{\circ} \mathrm{C}$ for 30 minutes. Hemagglutination test was carried out www.tropicalplantresearch.com 
against $2 \%$ RBC's with different temperature ranges. The temperature for maximum stability was determined by plotting graph of temperature range against percentage agglutination.

Effect of different metal ions: The metal ion requirement by purified lectins from extracts was determined by treating extracts with different metal ions (Kawagishi et al. 1990). $100 \mu$ of extracts were incubated with $400 \mu 1$ of $10 \mathrm{mM}$ EDTA (pH 5) at $4^{\circ} \mathrm{C}$ for 20 hours. Then extracts were dialyzed against $25 \mathrm{mM}$ sodium phosphate buffer (pH 7). $50 \mu \mathrm{l}$ of dialyzed samples was treated with $50 \mu \mathrm{l}$ of $1 \mathrm{mM} \mathrm{Mg}^{+}, \mathrm{Ca}^{+}, \mathrm{Hg}^{+}, \mathrm{Al}^{+}$ions and incubated for $2 \mathrm{hr}$ and hemagglutination assay was performed as above described standard protocol.

Native Polyacrylamide Gel Electrophoresis: Native PAGE was performed to determine the molecular weight of lectins from leaves, fruit, calyx and stem of CP. 10\% running gel and 5\% stacking gel was used with a standard marker protein (Serva Unstained SDS PAGE Protein Marker, 6.5-200kDa- catalogue no.39215.01). After electrophoresis, the gel was kept in fixative for $30 \mathrm{~min}$. and then stained with $0.2 \%$ coomassie brilliant blue (R250) for overnight, Finally, the gel was destained in $10 \%$ acetic acid until the background gets cleared and then analysed in densitometer (Bio Rad. PD Quest Software - 8.0.1)

\section{RESULTS}

Clerodendrum phlomidis L.f. was chosen on the basis of ample availability in surrounding campus and its unknown medicinal use to local people. The various parts of Clerodendrum phlomidis (CP) plant such as leaves, fruits, calyx; stem showed hemagglutination activity against human blood group as well as animal blood.

The method of ammonium sulphate partial purification (Ramteke \& Patil 2005, Mothong 2009) of plant lectins showed suitable saturation of $60-90 \%$ to precipitate almost total lectins from all parts of the plants.

\section{Protein estimation}

The protein content in extract of plants was found to be $10.3 \mathrm{mg} \cdot \mathrm{ml}^{-1}$ in CP leaves, $10.6 \mathrm{mg} \cdot \mathrm{ml}^{-1}$ in CP fruit, 10.0 mg. $\mathrm{ml}^{-1}$ in CP Calyx and CP Stem.

\section{Heamaglutination activity of isolated CP lectins}
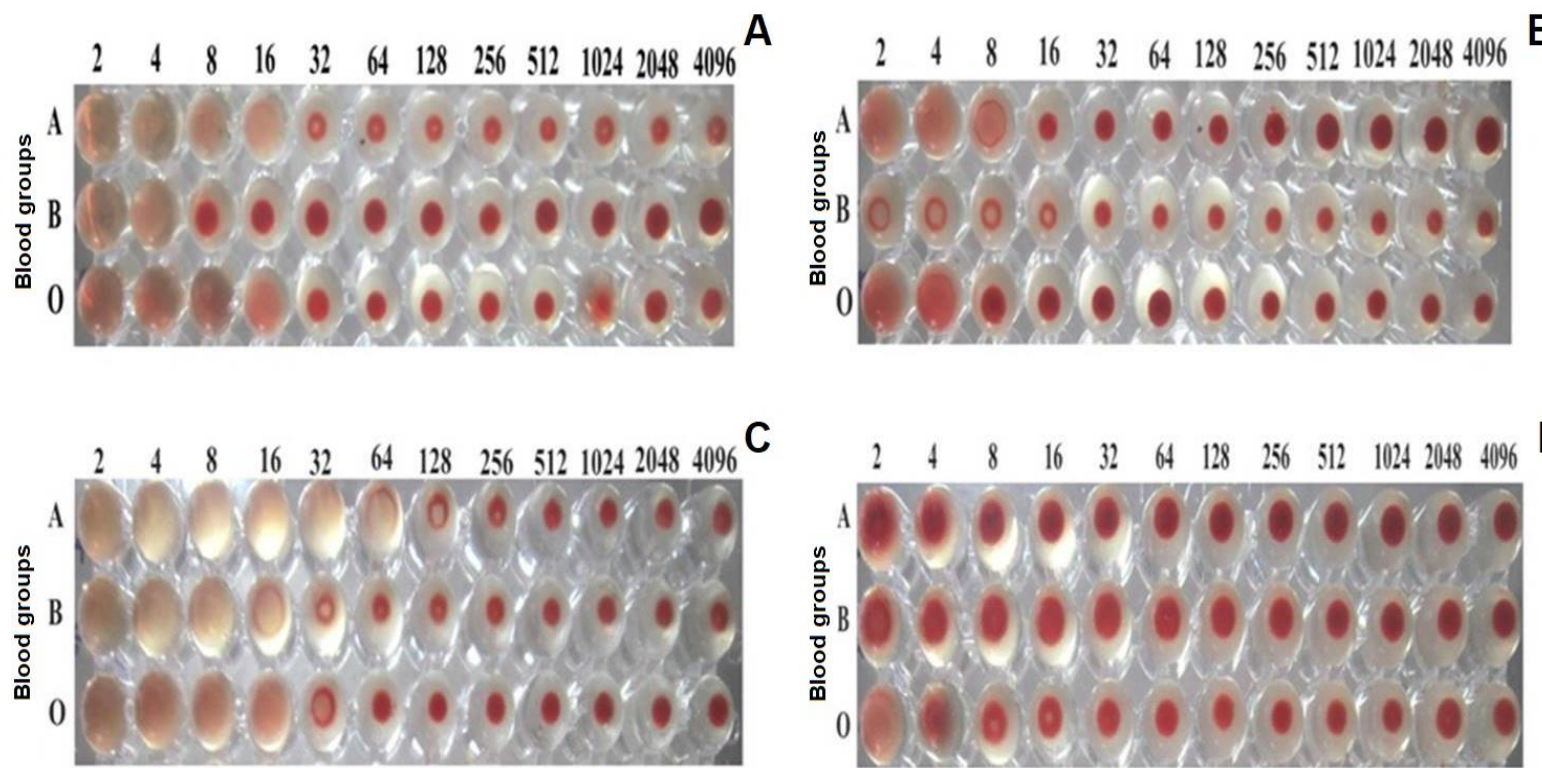

Figure 1. Hemagglutinationtiter of partially purified extract of Clerodendrum phlomidis L.f.: A, Leaves; B, Calyx; C, Fruits; D, Stem.

Hemagglutination Assay: Hemagglutination titer with serial dilution of all extracts against human blood group was performed. In case of CP leaves A and O blood group showed carpet pattern till sixteen times dilution while B blood group showed carpet pattern till eight times dilution. CP fruit had given carpet till sixty-four times with A blood group and sixteen times in both B and O blood groups. Calyx from the same plant had given carpet pattern up to four times dilutions in $\mathrm{A}$ and $\mathrm{O}$ while two times with $\mathrm{B}$ blood group. $\mathrm{CP}$ stem had given four times dilution carpet with A blood group and upto eight times with B and O groups. The hemagglutination titer is shown in figure 1. On the basis of titre, Hemagglutination Unit (HAU) and Specific Activity (SA) was calculated which is presented in table 1 . 
Table 1. Hemagglutination Unit (HAU) and Specific Activity (SA) calculations of partially purified lectins in leaves, calyx, fruits and stem of Clerodendrum phlomidis L.f.

\begin{tabular}{|c|c|c|c|c|c|c|c|}
\hline \multirow{2}{*}{$\begin{array}{l}\text { Dialyzed } \\
\text { extract }\end{array}$} & \multirow{2}{*}{$\begin{array}{l}\text { Estimated Protein } \\
\left(\mathrm{mg}^{\left.-\mathrm{ml}^{-1}\right)}\right.\end{array}$} & \multicolumn{3}{|c|}{ HAU.ml ${ }^{-1}$} & \multicolumn{3}{|c|}{ SA } \\
\hline & & 'A' & 'B' & 'O' & 'A' & 'B' & ' $O$ ' \\
\hline CP leaves & 10.3 & 164.8 & 412 & 164.8 & 16 & 40 & 16 \\
\hline CP fruits & 10.6 & 678.4 & 169.6 & 169.6 & 64 & 16 & 16 \\
\hline CP calyx & 10.0 & 40 & 20 & 40 & 4 & 2 & 4 \\
\hline CP stem & 10.0 & 40 & 80 & 80 & 4 & 8 & 8 \\
\hline
\end{tabular}

Agglutination pattern of extracts with different blood group such as human and various animals is depicted in table 2. All the extracts of CP showed strong hemagglutination activity against human blood group as well as some of the animal blood such as dog, hen, goat, mouse, mice and fish. It indicates along with human red blood cells, animal blood cells also present carbohydrate moieties which act as a ligand for plant lectins.

Table 2. Agglutination of human and animal erythrocytes by partially purified lectins from leaves, calyx, fruits and stem of Clerodendrum phlomidis L.f.

\begin{tabular}{lclll}
\hline Erythrocytes & CP Leaves & CP Fruit & CP Calyx & CP Stem \\
\hline Human 'A' & ++ & + & + & + \\
Human 'B' & ++ & ++ & ++ & + \\
Human' 'O' & ++ & ++ & + & + \\
Dog & + & + & + & + \\
Hen & + & + & + & + \\
Goat & + & + & + & + \\
Mouse & + & + & + & + \\
Mice & + & + & + & + \\
Fish & + & + & + & + \\
\hline
\end{tabular}

Hemagglutination Inhibition assay: Carbohydrate binding specificity or carbohydrate-affinity of lectin of CP was examined in this inhibition experiment. Different sugars like D-Glucose, Sucrose, Lactose, Sorbitol, DFructose, D-Maltose, D-Arabinose, D-Galactose, D-Xylose, D-Mannose and D-Ribose were used for determination of inhibition of hemagglutination of lectin activity. Lactose was found to be the only inhibitor of agglutination activity in $\mathrm{CP}$ plant extracts.

Further with lactose as the only inhibitor of hemagglutination activity, hemagglutination titer with various dilutions of lactose was performed. The minimum concentration required to inhibit the agglutination of different extracts is shown in table 3 .

The values shown in the table 3 indicated that the leaves and fruits lectins activity can be inhibited by lactose at lowest dilution of 125, at the same time activity inhibition for Calyx and Stem is 62.5 and 15.62 respectively.

Table 3. Inhibition of hemagglutination with different sugars.

\begin{tabular}{lllll}
\hline \multirow{2}{*}{ Sugars } & \multicolumn{4}{l}{ Minimum concentration required to inhibit the hemagglutination (mM) } \\
\cline { 2 - 5 } & CP Leaves & CP Fruits & CP Calyx & CP Stem \\
\hline D-Arabinose & NI & NI & NI & NI \\
D-Mannose & NI & NI & NI & NI \\
Lactose & 125 & 125 & 62.5 & 15.62 \\
D-Xylose & NI & NI & NI & NI \\
D-Galactose & NI & NI & NI & NI \\
Sorbitol & NI & NI & NI & NI \\
D-Maltose & NI & NI & NI & NI \\
Sucrose & NI & NI & NI & NI \\
D-Glucose & NI & NI & NI & NI \\
D-Fructose & NI & NI & NI & NI \\
D-Ribose & NI & NI & NI & NI \\
\hline
\end{tabular}

Note: NI, No Inhibition; CP, Clerodendrum phlomidis L.f..

\section{Characterization of CP lectins}

Optimization of $\mathrm{pH}$ for Hemagglutination activity of lectins: The varied $\mathrm{pH}$ stability of lectins and overlapping of the ranges were observed. The leaves of $\mathrm{CP}$ plant showed a wide range of stability in 4-10 $\mathrm{pH}$ indicating activity in acidic as well as basic $\mathrm{pH}$. The calyx and stem of $\mathrm{CP}$ plant showed $\mathrm{pH}$ stability between $4-8 \mathrm{pH}$ range. The fruits lectins were stable in the range between 5-7 pH. Figure 2 depicted the graphical representation of $\mathrm{pH}$ stability of lectins. 
A

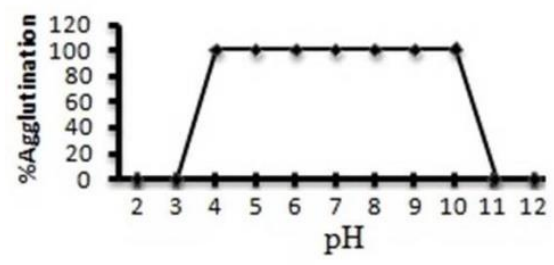

C

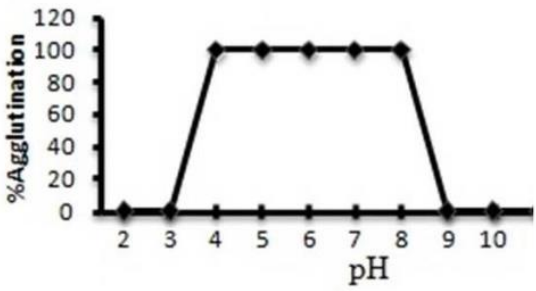

B
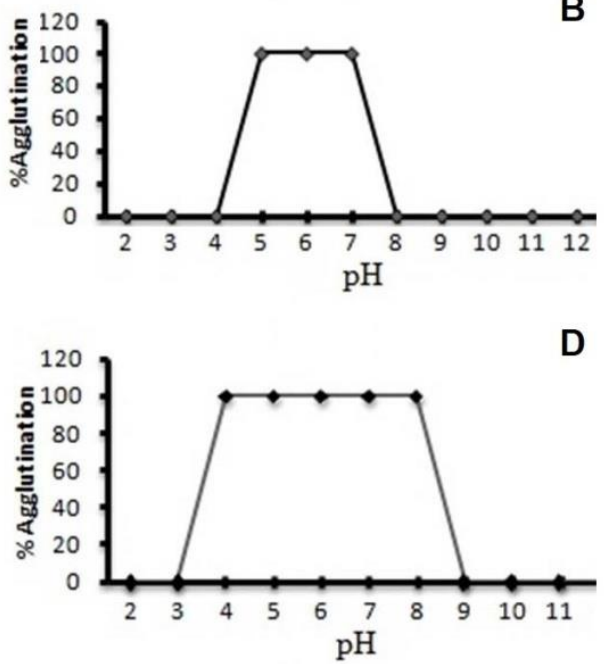

Figure 2. The graphical representation of $\mathrm{pH}$ stability of lectins in Clerodendrum phlomidis L.f: A, Leaves; B, Fruits; C, Calyx; D, Stem.

Optimization of Temperature for Hemagglutination activity of lectins: The results of the CP plant leaves showed $100 \%$ hemagglutination to the $40^{\circ} \mathrm{C}$ temperature. Further increase in temperature resulted in the reduction of activity of lectins. Fruits lectins were found to be active up to $50^{\circ} \mathrm{C}$. In case of $\mathrm{CP}$ calyx and stem, lectins were actively showing hemagglutination until $60^{\circ} \mathrm{C}$ and start to diminish from $70^{\circ} \mathrm{C}$ onwards. The activity of lectins in temperature variation is presented in figure 3.

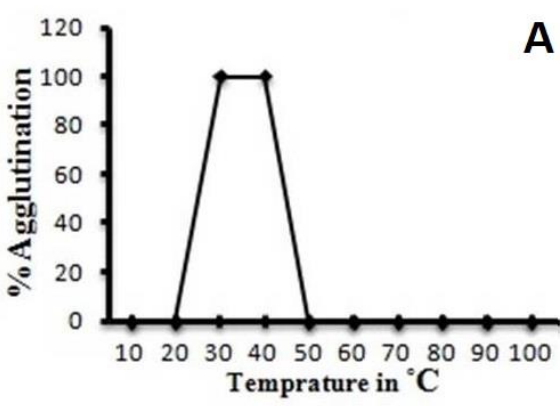

C

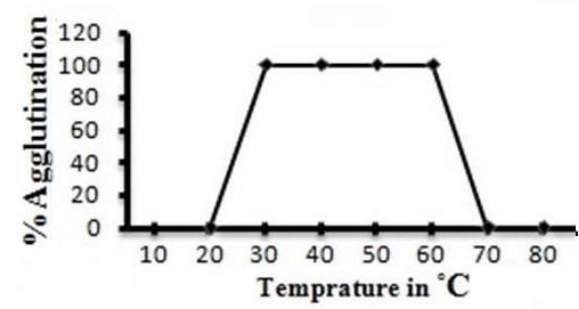

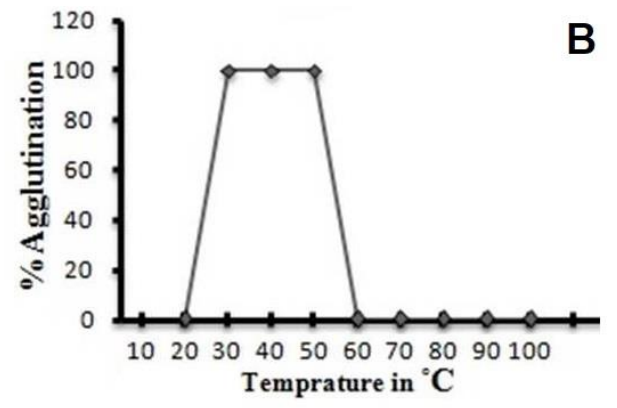

D

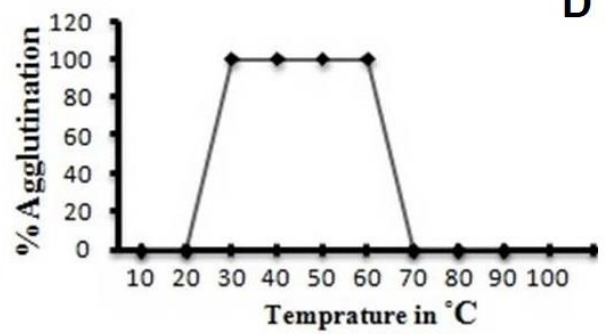

Figure 3. The graphical representation of temprature stability of lectins in Clerodendrum phlomidis L.f: A, Leaves; B, Fruits; C, Calyx; D, Stem.

\section{Effect of Metal Ions on Hemagglutination}

Table 4. Effect of metal ions (1mM) on agglutination of partially purified extracts.

\begin{tabular}{lllll}
\hline Metal Ions & CP Leaves & CP Fruits & CP Calyx & CP Stem \\
\hline Calcium & - & - & - & - \\
Magnesium & ++ & ++ & ++ & ++ \\
Mercury & ++ & ++ & ++ & ++ \\
Aluminium & + & + & + & + \\
\hline
\end{tabular}

Note: ++, Sign indicates hemagglutination; +, sign indicates slight hemagglutination; -, sign indicates no hemagglutination and hemolysis.

The effect of metal ions on hemagglutination activity of plant lectins was observed in EDTA treated extracts against metal salts and 2\% RBC's. The treatment with calcium salt hemolysed the RBC's. Mercuric chloride and magnesium chloride treatment was not effective to inhibit hemagglutination whereas Aluminium has shown www.tropicalplantresearch.com 
light button pattern indicating partial inhibition of agglutination possed by Aluminium ions. Table 4 showed the results of effects of metal ion $(1 \mathrm{mM})$ on agglutination of partially purified extracts.

\section{Native Polyacrylamide Gel Electrophoresis}

Native PAGE of the partially purified lectins from CP leaves, CP Fruit, CP Calyx and CP Stem gave protein band with molecular weight CP leaves $67 \mathrm{kDa}$ and $21 \mathrm{kDa}, \mathrm{CP}$ Fruit 70 and $21 \mathrm{kDa}, \mathrm{CP}$ Calyx and CP Stem 70, 50 and $45 \mathrm{kDa}$ (Fig. 4).

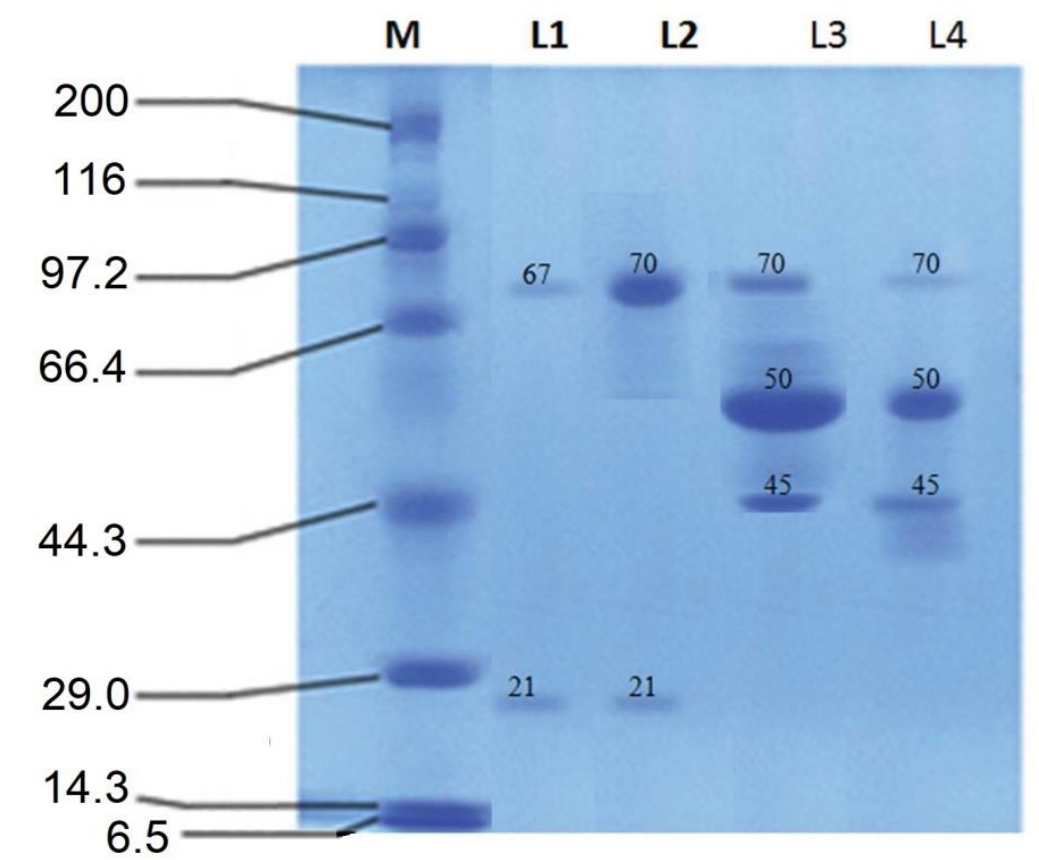

Figure 4. Band pattern of lectins Marker (M), CM Leaves (L1), CM Fruit (L2), CM Calyx (L3), CM Stem (L4) on Native PAGE.

\section{DISCUSSION AND CONCLUSION}

The present study focused on isolation and characterisation of lectins form Clerodendrum phlomidis L.f. plant. Most of the lectins those agglutinates erythrocytes are not specific towards blood groups, for example, wheat germ agglutinins (Nagata \& Burger 1974). With the same line obtaimed lectins of the CP plant are not specific for blood groups, it can be infered that lectin specific glycoconjugates or glycorecepters are not present on cell surface or vice varsa. It is known that, phytolectins have property to specifically bind glycoconjugates on the cell surface and agglutinates RBCs of human as well as animals. Plant extract also agglutinates some of the animal erythrocytes which is supported by study of Euphorbia tithymaloids by Jawade et al. (2016), Ahmed \& Cahtterjee (1987) and with Tridax procumbans by Ramteke \& Patil (2005).

Many lectins are specific for their carbohydrate ligands with different specificity. In a report by Chumkhunthod et al. (2006) Schizophyllum commune lectin has shown specificity towards N-acetyl-Dgalactosamine. To identify specific legands for lectins of the present sudy, hemagglutination inhibition assay was performed. The results indicated that CP lectins is lactose specific. The effect of lactose dilution was examined by serially diluting $500 \mathrm{mM}$ lactose. The agglutination in case of leaves and fruits was inhibited at 4 times dilution while at 8 times and 16 times in case of calyx and stem respectively.

Optimization of $\mathrm{pH}$ is one of the important factor responsible for the structure of proteins. In the present study, CP leaves lectins have shown a wide range of $\mathrm{pH}$ stability between $4-10$. Calyx and stem lectins have $\mathrm{pH}$ stability between 4-8 while fruit lectins are active within narrow range of $\mathrm{pH} 5-7$. This indicates that leaves lectins is compatible and active not only in highly acidic but also at highly basic $\mathrm{pH}$. Almost similar results were reported by Osukoya (2016) on the lectins of the fruit of cola nitida, kola nut.

The optimum temperature for maximum activity of $\mathrm{CP}$ calyx and stem lectins is shown upto $60^{\circ} \mathrm{C}$ and it loses its activity at $70^{\circ} \mathrm{C}$ onwards. Whereas lectins from Vigna mungo (Suseelan et al. 1997) and Erythrinaveluntina, Jackfruit (Artocarpus integrifolia) lectins (Ahmed \& Cahtterjee 1987) were stable at $70^{\circ} \mathrm{C}$. Lectins from $\mathrm{CP}$ leaves and fruits are stable upto $50^{\circ} \mathrm{C}$ and $60^{\circ} \mathrm{C}$ respectively. From the above results we can conclude that $\mathrm{CP}$ leaves lectins is tolerant for $\mathrm{pH}$ but not for temperature. 
In metal ion inhibition assay only aluminium metal ion has shown partial hemagglutination inhibition with EDTA treated extracts. At the same time, Tridax procumbens calyx lectin inhibit hemagglutination activity by Mercury (Ramteke \& Patil 2005). The partially purified lectins from CP leaves, CP fruits, CP calyx and CP stem showed multiple bands on Native PAGE with molecular wiegth $70 \mathrm{kDa}, 67 \mathrm{kDa}, 50 \mathrm{kDa}, 45 \mathrm{kDa}$ and 21 $\mathrm{kDa}$. The $70 \mathrm{kDa}$ bands were observed in all the parts of the plant. It can be speculated that the MW of the lectins is similar in all the parts of the plant.

Now a days, study on Lectins has been diverted towards their use in the development of blood grouping tool, cancer therapeutics, antimicrobial and antiparasitic agents and many more diagnostic tools and curative drug development areas. In the present work, we have screened CP lectins for the basic physical and chemical characters. Further study on molecular charcterisation and activity of isolated lectins against the microbial system, cancer cells, Diabetic cells and Immunogenicity can help us to introduce multiple uses of CP lectin in future.

\section{ACKNOWLEDGEMENT}

Authors are thankful to Director, National Institute of Miner's Health for their constant support and encouragement. We are also thankful to the people who donate blood samples for our study.

\section{REFERENCES}

Ahmed H \& Cahtterjee BP (1987) Further characterization and immunochemical studies on the carbohydrate specificity of jackfruit (Artocarpus integrifolia) lectin. The Journal of Biological Chemistry 264(16): 93659372.

Célia RC \& Grossi-de-Sa’ MF (2002) Plant toxic proteins with insecticidal properties. A review on their potentialities as bioinsecticides. Toxicon 40: 1515-1539.

Chumkhunthod P, Rodtong S, Lambert SJ, Fordham-Skelton AP, Rizkallah PJ, Wilkinson MC \& Reynolds CD (2006) Purification and characterization of an N-acetyl-D-galactosamine-specific lectin from the edible mushroom Schizophyllum commune. Biochimica et Biophysica Acta 1760: 326-332.

Deshpande K (2003) Studies of lectins of wild medicinal plant, Ph.D. Thesis. Nagpur University, Nagpur, Maharashtra, India.

Goldstein IJ \& Poretz RD (1986) Isolation, physicochemical characterization, and carbohydrate-binding specificity of lectins. In: Liener IE, Sharon N \& Goldstein IJ (eds) The Lectins. Academic Press, Orlando, pp. 33-247.

Gomall AG, Bardawill CJ \& David MM (1949) Determination of serum proteins by means of the Biuret reaction. The Journal of Biological Chemistry 177: 751-766.

Jawade AA, Pingle SK, Tumane RG, Sharma AS, Ramteke AS \& Jain RK (2016) Isolation and characterization of lectin from the leaves of Euphorbia tithymaloides (L.). Tropical Plant Research 3(3): 634-641.

Kawagishi H, Nomura A, Mizuno T, Kimura A \& Chiba S (1990) Isolation and Characterization of lectin from Grifola Frondosa fruiting bodies. Biochimica et Biophysica Acta 1034(3): 247-252.

Kurokawa T, Tsuda M \& Sugino Y (1976) Purification and characterization of lectin from Wistaria floribunda seeds. The Journal of Biological Chemistry 251: 5686-5693.

Lam SK \& Ng TB (2010) Isolation and characterization of a French bean hemagglutinin with antitumor, antifungal and anti-HIV-1 reverse transcriptase activities and an exceptionally high yield. Phytomedicine 17: $457-462$.

Mothong N (2009) Lectins from straw mushroom cultivated in north-eastern Thailand, Ph.D. Thesis. Suranaree University of technology, Nakhon Ratchasima, Thailand.

Nagata Y \& Burger MM (1974) Wheat Germ Agglutinin: Molecular characteristics and specificity for sugarbinding. The Journal of Biological Chemistry 249: 3116-3122.

Olsen ID (1944) The use of lectins (Agglutinins) to study cell surface, Ph.D. Thesis. Columbia University, NewYork City, USA.

Osukoya O (2016) Physicochemical characterization of an hemagglutinating protein from the fruit of cola nitida, kolanut. Innovare Journal of Science 4(4): 13-15.

Peumans, WJ \& Van Damme EJM (1995) Lectin as plant defense proteins. Plant Physiology 109: 347-352.

Ramteke AP \& Patil MB (2005) Purification and characterization of Tridax procumbens calyx lectin. Biosciences Biotechnology Research Asia 3: 103-110. 
Sharon N \& Lis H (2004) Review History of lectins: from hemagglutinins to biological recognition molecules. vol. 14 no. $11,53 \mathrm{R}-62 \mathrm{R}$.

Sonawane SR, Deshpande PR, Pande PP \& Shahane VC (2014) Phytochemical \& Pharmacological activity of Agnimantha (Clerodendrum phlomidis linn.f) - A review. International Journal of Ayurvedic and Herbal Medicine 4(5): 1615-1621.

Suseelan KN, Bhatia AR \& Mitra R (1997) Purification \& characterization of two major lectins from Vignamungo. Journal of Biosciences 22(4): 439-455. 